\title{
Tanshinone IIA inhibits lipopolysaccharide-induced inflammatory responses through the TLR4/TAK1/NF-кB signaling pathway in vascular smooth muscle cells
}

\author{
ZHE MENG ${ }^{1}$, CHUN-YING SI ${ }^{2}$, SHUAI TENG $^{1}$, XIN-HUI YU ${ }^{3}$ and HAI-YU LI ${ }^{1}$ \\ ${ }^{1}$ Department of Cardiology, The First Affiliated Hospital of Zhengzhou University, Zhengzhou, Henan 450052; \\ ${ }^{2}$ Department of Cardiology, The First Affiliated Hospital of Henan University of TCM, Zhengzhou, Henan 450003; \\ ${ }^{3}$ Department of Thoracic Surgery, Taicang Affiliated Hospital of Soochow University, Taicang, Jiangsu 210023, P.R. China
}

Received January 16, 2018; Accepted February 7, 2019

DOI: $10.3892 /$ ijmm.2019.4100

\begin{abstract}
To aim of the present study was to determine whether Tanshinone IIA (Tan IIA) inhibits lipopolysaccharide (LPS)-induced inflammation in vascular smooth muscle cells (VSMCs) from rats and elucidate the underlying molecular mechanism. VSMCs were primarily cultured and then treated with LPS (1 $\mu \mathrm{g} / \mathrm{l})$ and Tan IIA (25, 50 and $100 \mu \mathrm{mol} / \mathrm{l})$ for $24 \mathrm{~h}$. Monocyte chemoattractant protein (MCP)-1, interleukin (IL)-6 and tumor necrosis factor (TNF)- $\alpha$ levels were detected by ELISA and reverse transcription-quantitative polymerase chain reaction. Nitric oxide (NO) production was measured using the Griess reaction. The expression of Toll-like receptor 4 (TLR4), nuclear factor (NF)- $\mathrm{B}$ (p65), and inducible NO synthase (iNOS), and the phosphorylation of transforming growth factor- $\beta$-activated kinase 1 (TAK1) were detected by western blot analysis. Tan IIA inhibited the LPS-induced expression of MCP-1, IL-6, and TNF- $\alpha$ in a concentration-dependent manner and inhibited iNOS-mediated NO production. In addition, Tan IIA suppressed the expression of TLR4, the phosphorylation of TAK1, and the nuclear translocation of NF- $\kappa \mathrm{B}$ (p65). The anti-TLR4 antibody and TAK1 inhibitor 5Z-7-oxozeaenol partially attenuated the LPS-induced expression of proinflammatory cytokines. In conclusion, Tan IIA inhibits LPS-induced inflammatory responses in VSMCs in vitro through the partial suppression of the TLR4/TAK1/NF- $\mathrm{B}$ signaling pathway.
\end{abstract}

Correspondence to: Dr Hai-Yu Li, Department of Cardiology, The First Affiliated Hospital of Zhengzhou University, 1 Jianshedong Road, Zhengzhou, Henan 450052, P.R. China

E-mail: mengzhenihao@163.com

Key words: Tanshinone IIA, lipopolysaccharide, inflammation, Toll-like receptor 4, transforming growth factor- $\beta$-activated kinase 1 , vascular smooth muscle cells

\section{Introduction}

A long-lasting and low-grade inflammatory response may serve a critical role in the pathogenesis of atherosclerosis, a multi-pathogenic process that occurs within arterial inner and middle walls $(1,2)$. In addition to macrophages, vascular smooth muscle cells (VSMCs) contribute to the progression of atherosclerosis by upregulating inflammatory factors and pathological proliferation (3). Lipopolysaccharides (LPS) are primarily located on the outer membrane of Gram-negative enteric bacteria and can increase the expression of various types of inflammation-associated cytokines, including monocyte chemoattractant protein (MCP)-1, interleukin (IL)-6 and tumor necrosis factor (TNF)- $\alpha$ in VSMCs $(4,5)$. These proinflammatory factors have all been proven to promote the progression of atherosclerosis and increase the number of vulnerable atherosclerotic plaques in several clinical trials (6). Therefore, controlling excessive inflammatory responses, especially inhibiting the proinflammatory cytokines expressed by VSMCs, may be an effective way to suppress the progression of atherosclerosis and enhance atherosclerotic plaque stability.

The Toll-like receptor (TLR) family are pattern recognition receptors that recognize pathogen-associated molecular patterns. A key member of this family is TLR4, which may be associated with the innate and adaptive immunity caused by various stimulants, such as LPS, low-density lipoprotein and heat shock protein (7). Initially, TLR4 was revealed to activate the host defense against invasive infection, but more recent evidence has indicated that activation of TLR4 contributes to the progression of atherosclerosis by inducing excessive inflammation (8). TLR4 overexpression has been observed in atherosclerotic plaques in human and animal models, and was accompanied with an increase in various pro-inflammatory factors, including MCP-1, IL-1 $\beta$ and IL-6 $(9,10)$. By contrast, suppression of TRL4 activation inhibited the progression of atherosclerotic plaques in TLR4 knockout models (11). TGF- $\beta$-activated kinase 1 (TAK1) belongs to the mitogen-activated protein kinase (MAPK) family and was initially observed to activate the phosphorylation of MAPK induced by morphogenetic protein and transforming growth factor 
(TGF) (12). As a downstream molecule in the TLR4 signaling pathway, TAK1 can induce the phosphorylation of inhibitor

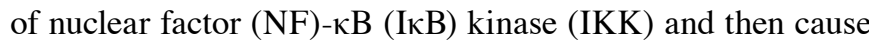
$\mathrm{NF}-\kappa \mathrm{B}$ activation, which may be a key mediator of various inflammatory responses. A previous study has suggested that inhibition of TAK1 activation suppresses LPS-induced inflammation (13).

Tanshinone IIA (Tan IIA) is primarily extracted from the root of Salvia miltiorrhiza Bunge, known as 'Danshen' in Chinese traditional medicine. For centuries Danshen has been used to treat cardiovascular diseases, including coronary heart disease (14). Tan IIA is an important constituent of Tans which are abietane-type norditerpenoid quinone natural products. Tan IIA has been shown to have various pharmacological effects, including anti-proliferation (15), anti-inflammation (16), anti-oxidation (17), and anti-tumor influences (18). Fan et al (19) described a Tan IIA anti-inflammatory effect on LPS-induced RAW264.7 cells, where the TLR4-MyD88-NF- $\kappa$ B signaling pathway was shown to impede microRNA expression and regulate the production of a series of cytokines. However, it is unknown if Tan IIA can inhibit LPS-induced inflammation in VSMCs or if Tan IIA's anti-inflammatory effects are associated with the TLR4/TAK1/NF- $\mathrm{KB}$ signaling pathway. Therefore, the aim of the present study was to define unknown molecular mechanisms that underpin the anti-inflammatory effects of Tan IIA, which may be beneficial for the treatment of coronary heart disease.

\section{Materials and methods}

Reagents. Tan IIA was obtained from the National Institute for the Control of Pharmaceutical and Biological Products (Beijing, China). The purity of Tan IIA was 99\%. Dulbecco's modified Eagle's medium (DMEM) and fetal bovine serum (FBS) were provided by Gibco (Thermo Fisher Scientific, Inc., Waltham, MA,USA).Penicillin, streptomycin, Tris-Buffered saline- $0.5 \%$ Tween, ethylenediaminetetraacetic acid (EDTA), LPS from Escherichia coli 0111:B4, pyrrolidine dithiocarbamate (PDTC), 3-[4,5-dimethylthiazol-2-yl]-2,5-diphenyltetrazolium bromide (MTT) and the enhanced chemiluminescence (ECL) kit were purchased from Sigma-Aldrich (Merck KGaA, Darmstadt, Germany). Calbiochem (Merck KGaA) was the commercial provider of 5Z-7-oxozeaenol (cat. no. 499610). Antibodies against TLR4, inducible nitric oxide (NO) synthase (iNOS), TAK1, phosphorylated (p)-TAK1, $\alpha$-SMA, osteopontin (OPN), $\mathrm{NF}-\kappa \mathrm{B}$ (p65), p47phox, I $\mathrm{B} \alpha, \mathrm{p}-\mathrm{I} \kappa \mathrm{B} \alpha$, anti-rabbit horseradish peroxidase (HRP)-conjugated, anti-mouse HRP-conjugated and histone were purchased from Santa Cruz Biotechnology, Inc. (Dallas, TX, USA). Transzol, EasyScript Reverse Transcriptase, TransStrat Green Qpcr SuperMix, 2X Power Taq PCR MasterMix and SYBR-Green, and the $\beta$-actin antibody were purchased from Beijing Transgen Biotech Co., Ltd. (Beijing, China). MCP-1, IL-6, and TNF- $\alpha$ enzyme-linked immunosorbent assay (ELISA) kits were purchased from Sigma-Aldrich (Merck KGaA).

VSMC culture. The present study was carried out in strict accordance with the Guide for the Care and Use of Laboratory Animals published by the US National Institutes of Health (NIHPublication no. 85-23, revised 1996) (20) and was approved by the Ethics and Animal Welfare Committee of Zhengzhou University (Henan, China). A total of 6 four-week-old male Sprague-Dawley rats (weighing 150-200 g) were obtained from the Laboratory Animal Institute of Zhengzhou University and were housed in a temperature $\left(22^{\circ} \mathrm{C}\right)$ and humidity $(55 \%)$ controlled animal facility maintained with a 12 -h light/dark cycle and ad libitum access to food and water. Experiments were conducted during the light phase of the cycle. VSMCs were isolated from the thoracic aorta of rats as previously described (21). Cells were cultured in DMEM containing $15 \% \mathrm{FBS}, 100 \mu \mathrm{g} / \mathrm{ml}$ streptomycin and $100 \mathrm{U} / \mathrm{ml}$ penicillin in a humidified atmosphere of $5 \% \mathrm{CO}_{2}$ and $95 \%$ air at $37^{\circ} \mathrm{C}$. Morphological examination was used to identify VSMCs. Cells between passage 3 and passage 11 were used for all experiments. When the cells reached $80-95 \%$ confluence, the medium was replaced with serum-free medium, and cells were cultured for $12 \mathrm{~h}$ prior to subsequent experiments.

Cell viability assay. VSMCs were seeded at a density of 5,000 cells/well in 96-well plates containing $100 \mu \mathrm{l}$ DMEM with $15 \%$ FBS and incubated for $12 \mathrm{~h}$. Tan IIA was dissolved in dimethylsulfoxide (DMSO). Cell viability was determined by an MTT reduction assay. The cells were either treated with Tan IIA at the indicated concentrations $(0,6.25,12.5,25,50$, 100 and $200 \mu \mathrm{mol} / \mathrm{l})$ for $24 \mathrm{~h}$ at $37^{\circ} \mathrm{C}$, or cells were pretreated with Tan IIA $(0,6.25,12.5,25,50,100$ and $200 \mu \mathrm{mol} / \mathrm{l})$ and then stimulated with LPS $(1 \mu \mathrm{g} / \mathrm{ml})$ for $24 \mathrm{~h}$ at $37^{\circ} \mathrm{C}$. The medium was removed and cells were then incubated with MTT solution $(5 \mathrm{mg} / \mathrm{ml})$ for $4 \mathrm{~h}$ at $37^{\circ} \mathrm{C}$. The dark blue formazan crystals that formed within and on intact cells were solubilized with $150 \mu \mathrm{l}$ of DMSO, and then the absorbance was measured at $490 \mathrm{~nm}$ on a microplate reader (Bio-Rad Laboratories, Inc., Hercules, CA, USA).

ELISA. VSMCs were seeded at a density of $5 \times 10^{6}$ cells/well in 6-well plates. Cells were pretreated with Tan IIA $(5,10$ or $30 \mu \mathrm{mol} / \mathrm{l})$ for $1 \mathrm{~h}$, then LPS $(1 \mu \mathrm{g} / \mathrm{ml})$ was added to the VSMC culture medium for $24 \mathrm{~h}$. VSMCs were pretreated with an antibody against TLR4 (1:250; cat. no. 542-0006), the TAK1 inhibitor 5Z-7-oxozeaenol $(0.5 \mu \mathrm{mol} / \mathrm{l})$, and PDTC $(100 \mu \mathrm{mol} / \mathrm{l})$ for $1 \mathrm{~h}$ at $37^{\circ} \mathrm{C}$ and were then incubated with LPS $(1 \mu \mathrm{g} / \mathrm{ml})$ for an additional $24 \mathrm{~h}$ at $37^{\circ} \mathrm{C}$. The MCP-1, IL- 6 and TNF- $\alpha$ concentrations in the culture medium were measured using the aforementioned ELISA kits (MCP-1 kit: cat. no. BYK-1021R; IL-6 kit: cat. no. EK-0411; TNF- $\alpha$ kit: cat. no. BK-0657) at $37^{\circ} \mathrm{C}$, according to the manufacturer's instructions.

Measurement of NO production. The accumulation of nitrite, a stable precursor of NO in culture medium, was measured according to the Griess reaction, as described previously (22). Briefly, $50 \mu \mathrm{l}$ of the culture supernatant was mixed with $50 \mu \mathrm{l}$ of Griess reagent ( $0.1 \%$ naphthyl-ethylenediamine, $1 \%$ sulfanylamide, and $2.5 \%$ phosphoric acid) for $1 \mathrm{~min}$ at $37^{\circ} \mathrm{C}$. Absorbance was measured at $540 \mathrm{~nm}$ using a calibration curve with sodium nitrite standards. Fresh culture medium was used as a control.

Reactive oxygen species (ROS) production measurement. The 2',7'-dichloro-dihydro-fluorescein diacetate (DCFH-DA) assay 
kit was purchased from Biyuntian Biotechnology Research Institute (Jiangsu, China; cat. no. S0076) and was used to measure intracellular ROS levels, based on the ROS-dependent oxidation of DCFH to highly fluorescent dichlorofluorescein. DCFH (10 mmol/l) was dissolved in methanol and then diluted by a factor of 500 in Hanks' balanced salt solution (HBSS) to produce a $20 \mu \mathrm{mol} / 1 \mathrm{DCFH}$ solution. The cells were incubated with DCFH-DA for $1 \mathrm{~h}$ at $37^{\circ} \mathrm{C}$ and then treated with HBSS containing Tan IIA $(25,50$ or $100 \mu \mathrm{mol} / \mathrm{l})$ or LPS $(1 \mu \mathrm{g} / \mathrm{ml})$ for a further $90 \mathrm{~min}$ at $37^{\circ} \mathrm{C}$. Fluorescence was measured immediately at a wavelength of $485 \mathrm{~nm}$ for excitation and $528 \mathrm{~nm}$ for emission on an iMark ${ }^{\mathrm{TM}}$ Microplate Absorbance Reader (Bio-Rad Laboratories, Inc.).

Reverse transcription-quantitative polymerase chain reaction $(R T-q P C R)$. Once the cells were treated with Tan IIA at the indicated concentrations $(25,50$ and $100 \mu \mathrm{mol} / \mathrm{l})$ for $24 \mathrm{~h}$ at $37^{\circ} \mathrm{C}$, total RNA was extracted using a TransZol reagent and DNA was removed using a DNA-free kit (Ambion; Thermo Fisher Scientific, Inc.). The quality of mRNA was verified by performing denaturing agarose gel electrophoresis containing $1.5 \%$ formaldehyde. The total RNA concentration and purity were determined through UV-Vis spectroscopy using the Bio-Rad SmartSpec 5000 system (Bio-Rad Laboratories, Inc.). To synthesize cDNA, $1 \mu \mathrm{g}$ of total RNA was used in a $20 \mu 1$ reaction using oligo(dT)18 Primer and EasyScript Reverse Transcriptase kit (Thermo Fisher Scientific, Inc.). Reverse transcription reaction conditions were as follows: $37^{\circ} \mathrm{C}$ for $15 \mathrm{~min}$, then $85^{\circ} \mathrm{C}$ for $5 \mathrm{sec}$ with the reverse transcription reagent and enzyme, and then kept at $4^{\circ} \mathrm{C}$. Primers for rat MCP-1, IL-6, TNF- $\alpha$, iNOS, TLR4, p47phox and $\beta$-actin were chosen using the Beacon designer v4.0 (Premier Biosoft International, Palo Alto, CA, USA; Table I). $\beta$-actin was used as an endogenous control. The mRNA levels of MCP-1, IL-6, TNF- $\alpha$, TLR4, iNOS, and $\beta$-actin were performed using $2 X$ Power Taq PCR MasterMix and SYBR-Green (Beijing Transgen Biotech Co., Ltd.), and the ABI PRISM 7000 sequence detection PCR system (Applied Biosystems; Thermo Fisher Scientific, Inc.). The qPCR thermocycling conditions for MCP-1, IL-6, TNF- $\alpha$, TLR4, iNOS, and $\beta$-actin were as follows: $94^{\circ} \mathrm{C}$ for $5 \mathrm{~min}$, $94^{\circ} \mathrm{C}$ for $10 \mathrm{sec}, 60^{\circ} \mathrm{C}$ for $20 \mathrm{sec}$ and $72^{\circ} \mathrm{C}$ for $30 \mathrm{sec}$, followed by 40 cycles of denaturation for $150 \mathrm{sec}$ at $72^{\circ} \mathrm{C}$, annealing for $90 \mathrm{sec}$ at $40^{\circ} \mathrm{C}$ and extension from 60 to $94^{\circ} \mathrm{C}$, followed by $1^{\circ} \mathrm{C}$ for $1 \mathrm{sec}$. A single melting curve peak confirmed the presence of a single product. Results were expressed as fold differences relative to $\beta$-actin using the $2^{-\Delta \Delta \mathrm{Cq}}$ method (23).

Western blot analysis. Following cell treatment with Tan IIA at the indicated concentrations $(25,50$ and $100 \mu \mathrm{mol} / \mathrm{l})$ for $24 \mathrm{~h}$ at $37^{\circ} \mathrm{C}$, VSMC lysates were prepared with $200 \mu \mathrm{l}$ of ice-cold lysis buffer (pH 7.4; 50 mmol/1 HEPES, 5 mol/l EDTA, 100 mmol/1 $\mathrm{NaCl}, 1 \%$ Triton X-100, and protease inhibitor cocktail; Roche Diagnostics GmbH, Mannheim, Germany) in the presence of phosphatase inhibitors $(50 \mathrm{mmol} / 1$ sodium fluoride, $1 \mathrm{mmol} / \mathrm{l}$ sodium orthovanadate, $10 \mathrm{mmol} / \mathrm{l}$ sodium pyrophosphate and $1 \mathrm{nmol} / 1$ microcystin). The activated NF- $\mathrm{B}$ (p65) protein, located in the nucleus, was extracted using the Pierce NE-PER Nuclear and Cytoplasmic Extraction kit (Pierce; Thermo Fisher Scientific, Inc.). A bicinchoninic acid protein assay kit
Table I. Primers used for reverse transcription-quantitative polymerase chain reaction analysis.

\begin{tabular}{|c|c|}
\hline Gene & Oligonucleotide primer sequences $\left(5^{\prime}-3^{\prime}\right)$ \\
\hline \multirow[t]{2}{*}{ IL-6 } & Forward: GAGAAAAGAGTTGTGCAATGGC \\
\hline & Reverse: ACTAGGTTTGCCGAGTAGACC \\
\hline \multirow[t]{2}{*}{ TNF- $\alpha$} & Forward: TCCCAACAAGGAGGAGAAGT \\
\hline & Reverse: TGGTATGAAGTGGCAAATCG \\
\hline \multirow[t]{2}{*}{ MCP-1 } & Forward: TCTCACTTGGTTCTGGTCCAGT \\
\hline & Reverse: AGTCAGCGATGGCCCGATAG \\
\hline \multirow[t]{2}{*}{ iNOS } & Forward: CCACGCTCTTCTGTCTACTGAAC \\
\hline & Reverse: ACGGGCTTGTCACTCGAG \\
\hline \multirow[t]{2}{*}{ TLR4 } & Forward: GGCATCATCTTCATTGTCCTTG \\
\hline & Reverse: AGCATTGTCCTCCCACTCG \\
\hline \multirow[t]{2}{*}{ p47phox } & Forward: GGCAGGACCTGTCGGAGAAGGT \\
\hline & Reverse: AAGGATGATGGGGCCTGTGATG \\
\hline \multirow[t]{2}{*}{ GADPH } & Forward: ATCGGCAATGAGCGGTTCC \\
\hline & Reverse: AGCACTGTGTTGGCATAGAGG \\
\hline
\end{tabular}

IL-6, interleukin-6; TNF- $\alpha$, tumor necrosis factor- $\alpha$; MCP-1, monocyte chemoattractant protein 1 ; iNOS, inducible nitric oxide synthase; TLR4, Toll-like receptor 4.

was used to determine protein concentrations. A total of $30 \mu \mathrm{g}$ protein was loaded per lane, then samples were separated by $10 \%$ SDS-PAGE and transferred onto a polyvinylidene difluoride membrane in a semi-dry system (Bio-Rad Laboratories, Inc.), which was blocked with 5\% fat-free milk in TBST buffer (20 mmol/1 Tris- $\mathrm{HCl}, 137 \mathrm{mmol} / 1 \mathrm{NaCl}$ and $0.1 \%$ Tween-20) for $120 \mathrm{~min}$ at $37^{\circ} \mathrm{C}$. Membranes were then incubated with primary antibodies against TLR4 (1:500; cat. no. sc-2213), TAK1 (1:400; cat. no. sc-2501), p-TAK1 (1:500; cat. no. sc-1152), p47phox (1:400; cat. no. sc-0032), SMA (1:100; cat. no. sc-SC19483), OPN (1:100; cat. no. sc-03652), (1:1,000; cat. no. sc-0096), $\beta$-actin $(1: 2,000$; cat. no. sc-21764), histone $(1: 1,000$; cat. no. sc-1179), IкB $\alpha$ (1:100; cat. no. sc-89320) and $\mathrm{p}-\mathrm{I} \kappa \mathrm{B} \alpha(1: 100$; cat. no. sc-20076) in TBST buffer overnight at $37^{\circ} \mathrm{C}$, following which membranes were washed and then incubated with secondary antibodies (1:5,000; anti-rabbit HRP-conjugated; cat. no. sc-276002; anti-mouse; HRP-conjugated; cat. no. sc-450039) for $110 \mathrm{~min}$ at $37^{\circ} \mathrm{C}$. The optical densities of bands were quantified using the ECL kit (Sigma-Aldrich; Merck KGaA) and Gel-Pro Analyzer software version 4.0 (Media Cybernetics, Inc., Rockville, MD, USA). $\beta$-actin or histone were used as the endogenous control, and the results were expressed relative to their corresponding control and ultimately as fold differences compared with the control.

Statistical analysis. Results are expressed as the mean \pm standard error of the mean of six experiments. Differences between groups were assessed by one-way analysis of variance followed by least significant difference post hoc tests. Statistical tests were performed using SPSS 16.0 software (SPSS, Inc., Chicago, IL, USA). $\mathrm{P}<0.05$ was considered to indicate a statistically significant difference. 


\section{Results}

Cytotoxity of Tan IIA in VSMCs. Cells were treated with different concentrations of Tan IIA $(0-200 \mu \mathrm{mol} / \mathrm{l})$ or LPS $(1 \mu \mathrm{g} / \mathrm{ml})$ for $24 \mathrm{~h}$ and then cytotoxity was measured by an MTT assay. As shown in Fig. 1, 0-100 $\mu \mathrm{mol} / 1$ Tan IIA was not cytotoxic against VSMCs with or without LPS $(1 \mu \mathrm{g} / \mathrm{ml})$.

Tan IIA inhibits LPS-induced VSMC phenotypic switching. VSMC phenotypic switching is involved in the LPS-induced inflammatory response. When VSMCs transform from the contractile phenotype to the synthetic phenotype, they produce lower levels of contractile proteins (24), such as $\alpha$-SMA, and higher levels of OPN. As shown in Fig. 2A, following VSMC treatment with LPS $(1 \mu \mathrm{g} / \mathrm{ml})$ for $24 \mathrm{~h}$, the protein expression of $\alpha$-SMA decreased; however, OPN levels increased. Pretreatment with Tan IIA attenuated the downregulation of $\alpha$-SMA and suppressed the upregulation of OPN in LPS-stimulated VSMCs, in a concentration-dependent manner. Similar results were obtained from mRNA level measurements via RT-qPCR (Fig. 2B).

Tan IIA inhibits the LPS-induced expression of MCP-1, IL-6, and TNF- $\alpha$ in VSMCs. A significant increase in the expression of MCP-1, IL-6, and TNF- $\alpha$ in the conditioned media of VSMCs treated with LPS $(1 \mu \mathrm{g} / \mathrm{ml})$ for $24 \mathrm{~h}$ was observed. Treatment with Tan IIA inhibited the LPS-induced protein expression of MCP-1, IL-6, and TNF- $\alpha$ in VSMCs in a concentration-dependent manner (Fig. 3A-C). In addition, Tan IIA also reduced the mRNA expression of MCP-1, IL-6, and TNF- $\alpha$ in LPS-stimulated VSMCs in a concentration-dependent manner (Fig. 3D-F). However, treating cells with Tan IIA $(100 \mu \mathrm{mol} / \mathrm{l})$ alone did not affect either the mRNA or protein expression of these proinflammatory cytokines.

Inhibitory effect of Tan IIA on iNOS-mediated NO production in LPS-stimulated VSMCs. Results from the Griess assay revealed that Tan IIA inhibited LPS-induced NO production in VSMCs in a concentration-dependent manner. However, treating the cells with Tan IIA $(100 \mu \mathrm{mol} / \mathrm{l})$ alone did not affect NO production (Fig. 4). To investigate how Tan IIA decreased LPS-induced NO production, the expression of iNOS was measured. As shown in Fig. 4A and B, Tan IIA reduced the LPS-induced expression of iNOS at the mRNA and protein levels in a concentration-dependent manner. Treatment with Tan IIA alone did not affect the mRNA or protein expression of iNOS when compared with control. Similar results were observed when measuring the NO levels (Fig. 4C). These results suggest that iNOS activation may serve a role in the inhibitory effects of Tan IIA on LPS-induced NO production in VSMCs.

Tan IIA downregulates p47-phox and decreases ROS levels. p47-phox protein (Fig. 5A) and mRNA (Fig. 5B) expression, and ROS production (Fig. 5C) in cultured VSMCs were significantly increased by stimulation with LPS; this effect was dose-dependently inhibited by co-treatment with Tan IIA.
A
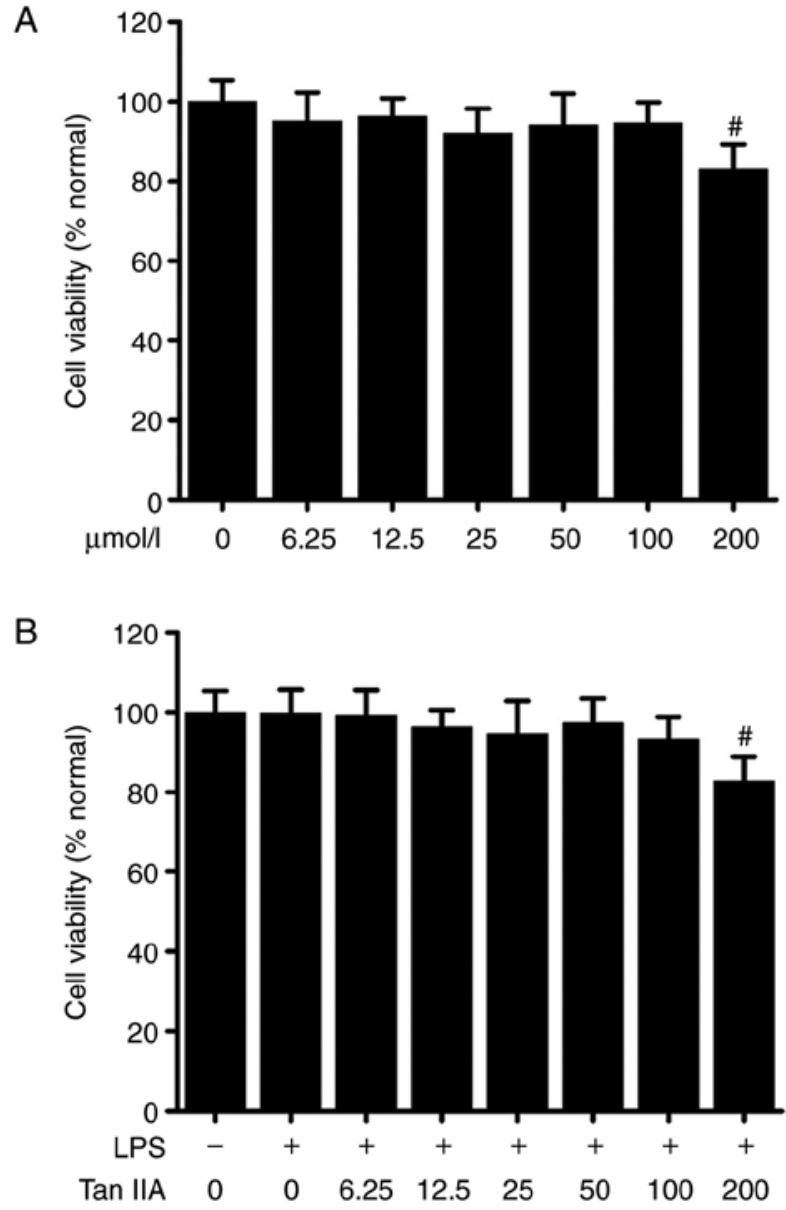

Figure 1. Cytotoxicity of Tan IIA in VSMCs. VSMCs were treated with different concentrations of Tan IIA (0-200 $\mu \mathrm{mol} / \mathrm{l})$ for $24 \mathrm{~h}$, (A) the results of the MTT assay indicated that Tan IIA concentrations between 0-100 $\mu \mathrm{mol} / 1$ had no influence on the viability of VSMCs. (B) Treating VSMCs with Tan IIA $(0-100 \mu \mathrm{mol} / 1)$ and LPS $(1 \mu \mathrm{g} / \mathrm{ml})$ for $24 \mathrm{~h}$ did not induce VSMC cytotoxicity; however, $200 \mu \mathrm{mol} / 1$ Tan IIA with $1 \mu \mathrm{g} / \mathrm{ml}$ LPS did significantly reduce cell viability. Data are presented as the mean \pm standard error of the mean from six independent experiments. ${ }^{\#} \mathrm{P}<0.001$ vs. control. Tan IIA, Tanshinone IIA; VSMCs, vascular smooth muscle cells; LPS, lipopolysaccharide.

As shown in Fig. 6A and B, LPS $(1 \mu \mathrm{g} / \mathrm{ml})$ treatment significantly increased the mRNA and protein expression of TLR4. Pretreatment with Tan IIA inhibited the LPS-induced expression of TLR4 at the mRNA and protein level in VSMCs (Fig. 6A and B). Treating VSMCs with Tan IIA (100 $\mu \mathrm{mol} / \mathrm{l})$ alone did not affect the expression of TLR4 (Fig. 6A and B). Next, the present study explored if the anti-inflammatory effect of Tan IIA on the LPS-induced expression of proinflammatory cytokines may function partially through TLR4 in VSMCs. Cells were treated with or without anti-TLR4 neutralizing antibody $(8 \mu \mathrm{g} / \mathrm{ml})$ for $1 \mathrm{~h}$, and then Tan IIA $(100 \mu \mathrm{mol} / \mathrm{l})$ was added and incubated for $1 \mathrm{~h}$. This was followed by LPS $(1 \mu \mathrm{g} / \mathrm{ml})$ stimulation in VSMCs for $24 \mathrm{~h}$. The TLR4 inhibitor and Tan IIA partially inhibited the LPS-induced increase in the levels of p-TAK1 (Fig. 6C), MCP-1 (Fig. 6D), TNF- $\alpha$ (Fig. 6E), IL-6 (Fig. 6F), and NO (Fig. 6G) in VSMCs. These results indicate that the inhibitory effect of Tan IIA on LPS-induced inflammation may be partially dependent on TLR4 in VSMCs. LPS-induced inflammation and TAK1 activation in VSMCs. 

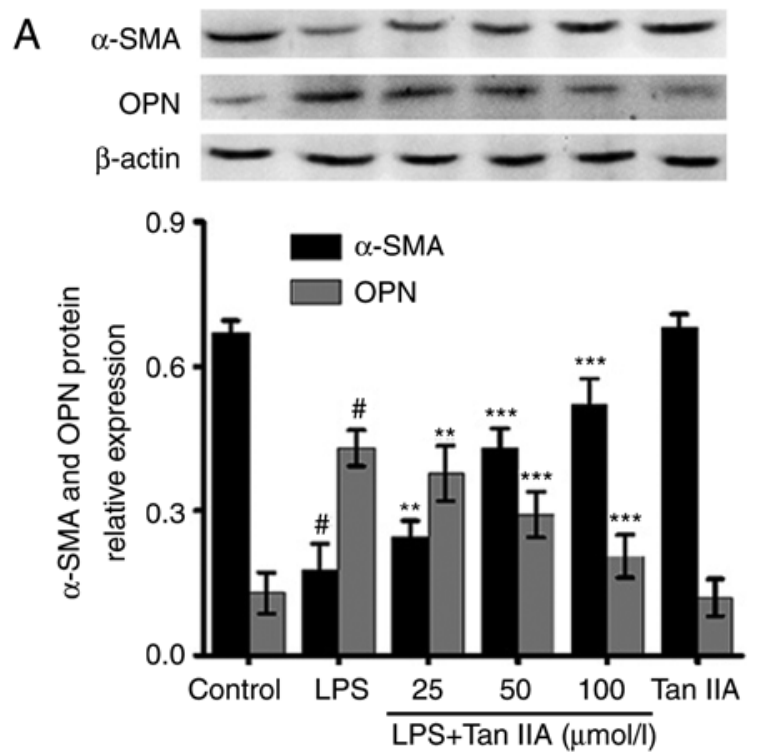

B

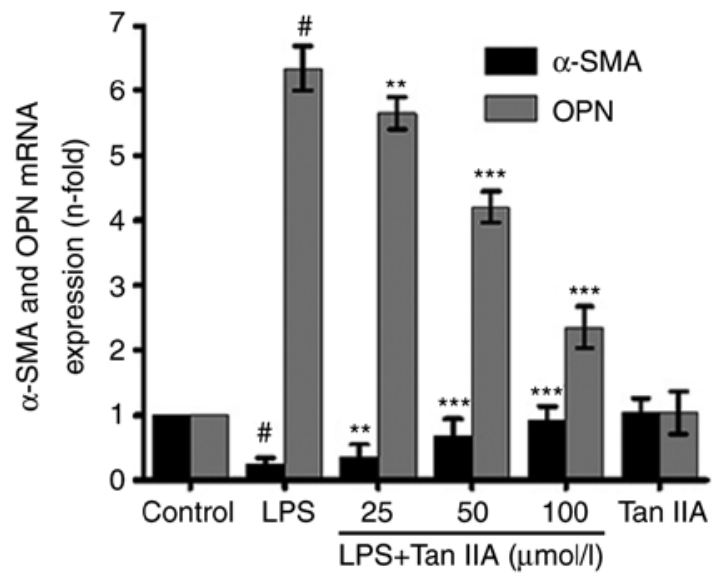

Figure 2. Tan IIA inhibits LPS-induced VSMC phenotypic switching. VSMCs were pretreated with the indicated concentrations of Tan IIA (25,50 and $100 \mu$ mol/1) for $1 \mathrm{~h}$, and then stimulated with LPS $(1 \mu \mathrm{g} / \mathrm{ml}$ ) for a further 24 (for western blotting) or $6 \mathrm{~h}$ (for RT-qPCR). The (A) protein and (B) mRNA expression of $\alpha$-SMA and OPN were measured by western blotting and RT-qPCR, respectively. Data are presented as the mean \pm standard error of the mean of six independent experiments. ${ }^{\#} \mathrm{P}<0.001$ vs. control; ${ }^{* *} \mathrm{P}<0.01$ and ${ }^{* * *} \mathrm{P}<0.001$ vs. LPS. Tan IIA, Tanshinone IIA; VSMCs, vascular smooth muscle cells; LPS, lipopolysaccharide; $\alpha$-SMA, $\alpha$-smooth muscle actin; OPN, osteopontin; RT-qPCR, reverse transcription-quantitative polymerase chain reaction.

To explore which intracellular signaling pathway downstream of TLR4 is involved in the inhibitory effect of Tan IIA on LPS-induced inflammation, the phosphorylation of TAK1 was detected in LPS-stimulated VSMCs. As shown in Fig. 7, treating VSMCs with different concentrations of Tan IIA $(25,50$ and $100 \mu \mathrm{mol} / \mathrm{l})$ alone did not affect the phosphorylation of TAK1. However, treatment with LPS $(1 \mu \mathrm{g} / \mathrm{ml})$ for 30 min significantly increased the levels of p-TAK1 in VSMCs (Fig. 7B). Pretreating the cells with Tan IIA attenuated the LPS-induced phosphorylation of TAK1 in a concentration-dependent manner (Fig. 7A and B). To determine if the inhibitory effect of Tan IIA on LPS-induced inflammation is dependent on the reduced expression of p-TAK1, the VSMCs were pretreated with or without $5 \mathrm{Z}-7$-oxozeaenol $(0.5 \mu \mathrm{mol} / \mathrm{l})$, which is a specific inhibitor of TAK1 activation. The results confirmed that 5Z-7-oxozeaenol significantly decreased p-TAK1 (Fig. 7B). In addition, 5Z-7-oxozeaenol and Tan IIA partially inhibited the LPS-induced expression of MCP-1, IL-6, TNF- $\alpha$ and NO in VSMCs (Fig. 7C-F). These results suggest that the reduction in p-TAK1 levels induced by Tan IIA may contribute to its anti-inflammatory influence on LPS-stimulated VSMCs.

Tan IIA inhibits LPS-induced NF- $\kappa B$ activation in VSMCs. The activation of $\mathrm{NF}-\kappa \mathrm{B}$ serves a key role in controlling the inflammatory response in various cell types, including VSMCs, by upregulating the expression of inflammatory genes. Following stimulation with different proinflammatory factors, including LPS, NF- $\kappa \mathrm{B}$ is activated and translocated from the cytoplasm to the nucleus (25). As shown in Fig. 8A, treating cells with different concentrations of Tan IIA alone for $24 \mathrm{~h}$ did not affect the nuclear translocation of $\mathrm{NF}-\kappa \mathrm{B}(\mathrm{p} 65)$. Treating VSMCs with LPS $(1 \mu \mathrm{g} / \mathrm{ml})$ for $24 \mathrm{~h}$ significantly increased the expression of NF- $\mathrm{BB}$ (p65) in the nucleus. However, pretreatment with Tan IIA attenuated the
LPS-induced nuclear translocation of NF- $\kappa \mathrm{B}$ in VSMCs in a concentration-dependent manner (Fig. 8A). By contrast, cytoplasmic $\mathrm{NF}-\kappa \mathrm{B}$ was decreased by LPS, which was reversed by co-treatment with Tan IIA (Fig. 8A). Furthermore, the present study measured the levels of total- and $\mathrm{p}-\mathrm{I} \kappa \mathrm{B} \alpha$, which is a negative regulator of $\mathrm{NF}-\kappa \mathrm{B}$, by western blot analysis. As shown in Fig. 8B, following VSMC treatment with LPS $(1 \mu \mathrm{g} / \mathrm{ml})$ for $6 \mathrm{~h}$, the total $\mathrm{I} \kappa \mathrm{B} \alpha$ levels decreased while $\mathrm{p}-\mathrm{I} \kappa \mathrm{B} \alpha$ levels significantly increased. Pretreating the cells with Tan IIA $(25,50$ and $100 \mu \mathrm{mol} / \mathrm{l})$ attenuated the LPS-induced decrease in total $\mathrm{I} \kappa \mathrm{B} \alpha$ and increase in $\mathrm{p}-\mathrm{I} \kappa \mathrm{B} \alpha$ in a concentration-dependent manner (Fig. 8B). Treatment of VSMCs with Tan IIA $(100 \mu \mathrm{mol} / \mathrm{l})$ alone did not affect the levels of total- and p-IкB $\alpha$ (Fig. 8B).

\section{Discussion}

The present study demonstrated that Tan IIA inhibits LPS-induced MCP-1, IL-6, TNF- $\alpha$ and iNOS-mediated NO production in VSMCs in vitro. Tan IIA also reduced the LPS-induced expression of TLR4 and TAK1 and reduced the nuclear translocation of $\mathrm{NF}-\kappa \mathrm{B}$ in a concentration-dependent manner. These results provide a novel association between the anti-inflammatory effect of Tan IIA and the TLR4/TAK1/NF- $\kappa$ B signaling pathway in LPS-stimulated VSMCs.

Multiple factors have been shown to contribute to the progression of atherosclerosis, but chronic low-grade inflammation may be a critical factor in the acceleration of atherosclerosis progression and plaque instability. Various inflammation-associated factors contribute to this process (1). MCP-1 is a potential monocyte chemoattractant cytokine that can induce the migration of monocytes and macrophages to the intima of the arterial walls and accelerate their development into foam cells (26). LPS is a powerful pro-inflammatory 

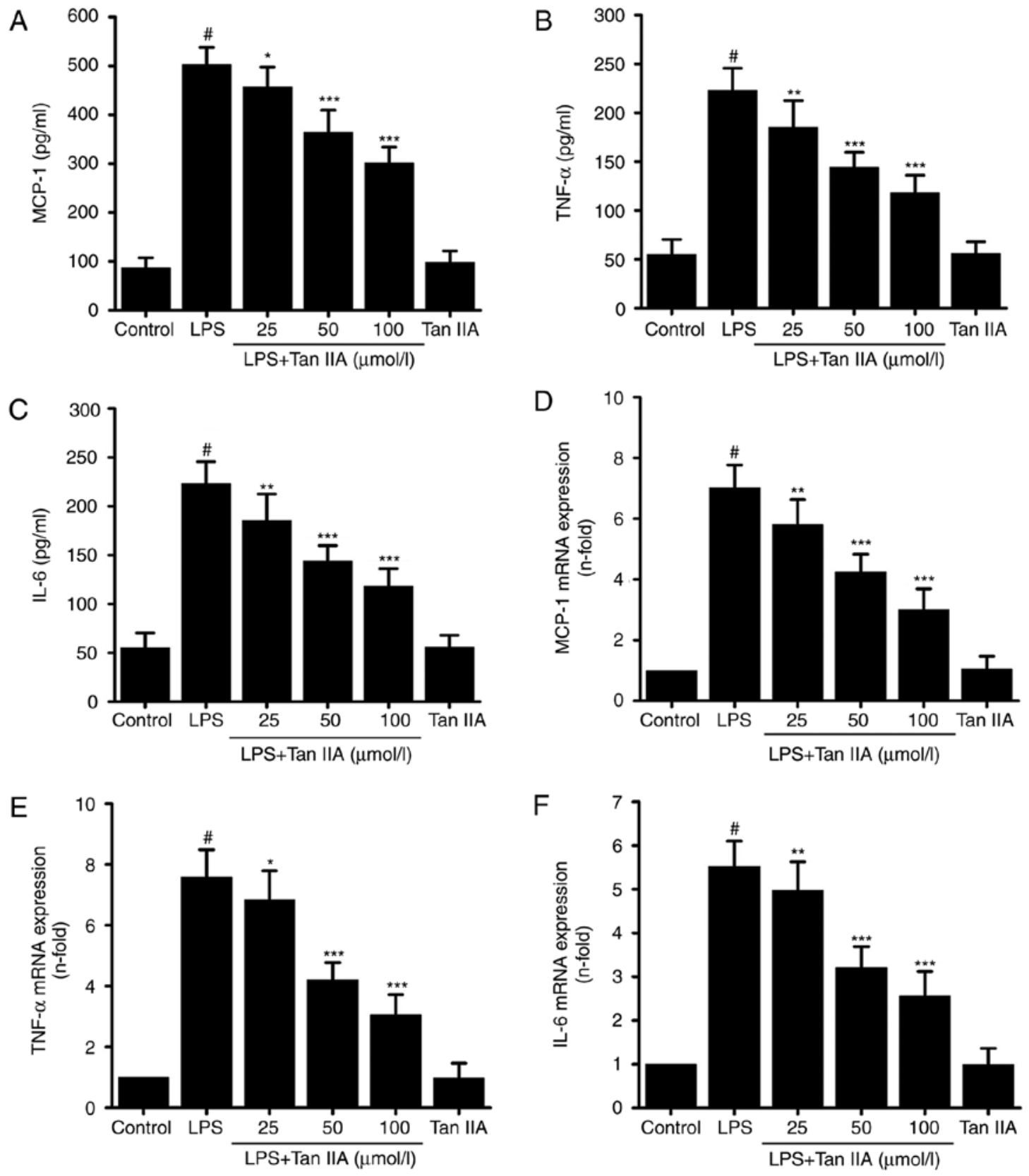

Figure 3. Tan IIA inhibits the LPS-induced expression of MCP-1, IL-6, and TNF- $\alpha$ in VSMCs. VSMCs were pretreated with the indicated concentrations of Tan IIA $(25,50$ and $100 \mu \mathrm{mol} / \mathrm{l})$ for $1 \mathrm{~h}$, and then stimulated with LPS $(1 \mu \mathrm{g} / \mathrm{ml})$ for a further $24 \mathrm{~h}$. One group of cells were treated with Tan IIA (100 $\mu \mathrm{mol} / 1)$ alone for $24 \mathrm{~h}$. The protein expression of (A) MCP-1, (B) TNF- $\alpha$ and (C) IL-6 was measured by an ELISA assay. Then cells were pretreated with the indicated concentrations of Tan IIA $(25,50$ and $100 \mu \mathrm{mol} / \mathrm{l})$ for $1 \mathrm{~h}$, and then stimulated with LPS $(1 \mu \mathrm{g} / \mathrm{ml})$ for a further $6 \mathrm{~h}$. The mRNA the expression levels of (D) MCP-1, (E) TNF- $\alpha$ and (F) IL-6 was measured by reverse transcription-quantitative polymerase chain reaction in which GAPDH was used as an internal control. Data are presented as mean \pm standard error of the mean of six independent experiments. ${ }^{*} \mathrm{P}<0.001$ vs. control; ${ }^{*} \mathrm{P}<0.05,{ }^{* * *} \mathrm{P}<0.01$ and ${ }^{* * * *} \mathrm{P}<0.001$ vs. LPS. Tanshinone IIA; VSMCs, vascular smooth muscle cells; LPS, lipopolysaccharide; IL-6, interleukin-6; TNF- $\alpha$, tumor necrosis factor- $\alpha$; MCP-1, monocyte chemoattractant protein 1 .

factor that can induce the expression of various inflammation-associated cytokines, including MCP-1, IL- 6 and TNF- $\alpha$, in VSMCs (4). In addition, there a growing body of evidence that indicates that there is a strong correlation between LPS and atherosclerosis (27). Tan IIA has been reported to have diverse pharmacological effects, including anti-inflammation, anti-apoptosis, and regulation of the immune response (28). Previous studies have indicated that Tan IIA may inhibit the LPS-induced expression of inflammation-associated cytokines in various cell types $(19,29,30)$. In the present study, LPS significantly increased the expression of MCP-1, IL-6, and TNF- $\alpha$ in VSMCs, which is consistent with a previous study (4). However, Tan IIA treatment could attenuate the LPS-induced expression of inflammation-associated cytokines in a dose-dependent manner, which may be a potential mechanism of the anti-inflammatory activity of Tan IIA. In addition, Tan IIA also inhibited the oxidized-low-density lipoprotein-induced inflammatory response in various organs (31), which suggests that Tan IIA has multiple anti-inflammatory activities against more than just LPS.

$\mathrm{NO}$ is mainly produced by the endothelium of the arterial walls, and it serves an important role in regulating inflammation 
A
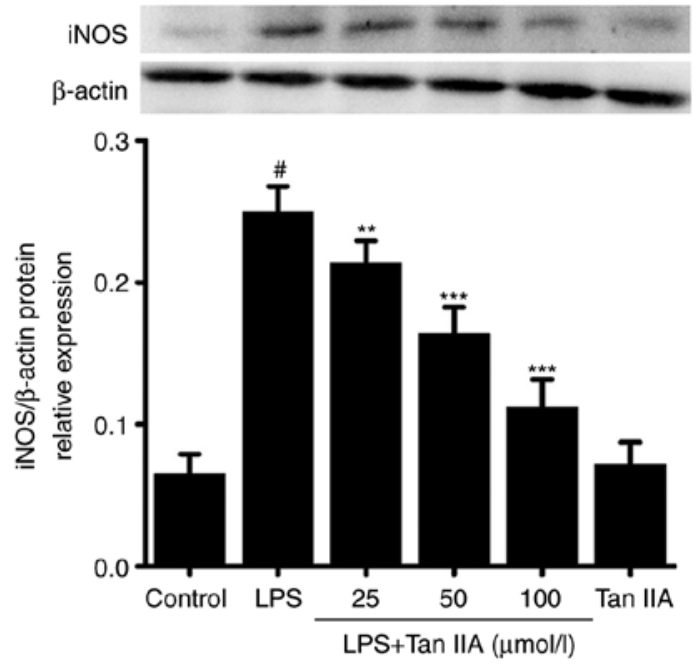

B

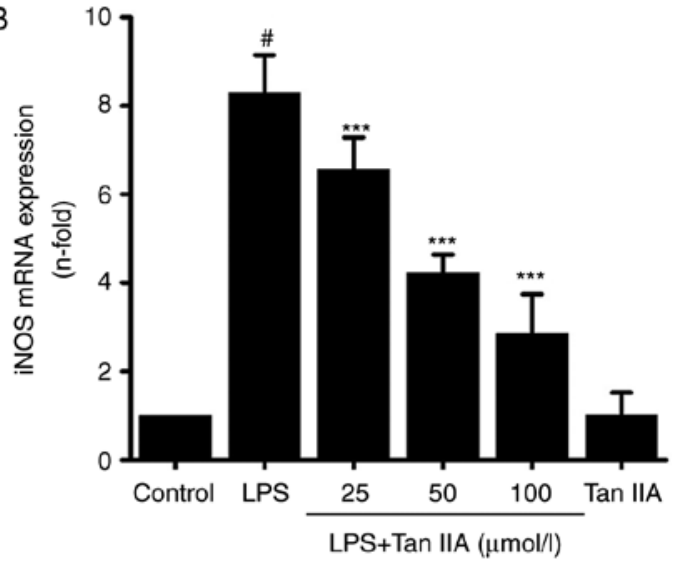

C

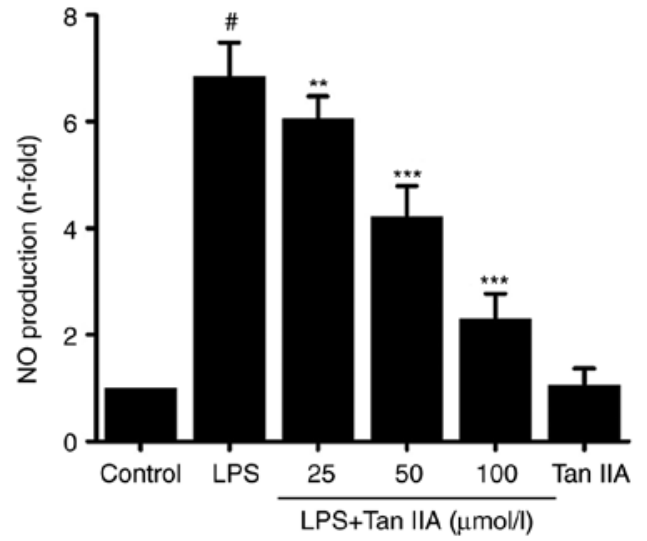

Figure 4. Inhibitory effect of Tan IIA on iNOS-mediated NO production in LPS-stimulated VSMCs. VSMCs were pretreated with the indicated concentrations of Tan IIA $(25,50$ and $100 \mu \mathrm{mol} / \mathrm{l})$ for $1 \mathrm{~h}$, and then stimulated with LPS $(1 \mu \mathrm{g} / \mathrm{ml})$ for a further $24 \mathrm{~h}$. One group of cells was treated with Tan IIA (100 $\mu \mathrm{mol} / \mathrm{l})$ alone for $24 \mathrm{~h}$. (A) iNOS proteins were detected by western blotting, in which $\beta$-actin was used as an internal control. Then cells were pretreated with the indicated concentration of Tan IIA $(25,50$ and $100 \mu \mathrm{mol} / 1)$ for $1 \mathrm{~h}$, and then stimulated with LPS $(1 \mu \mathrm{g} / \mathrm{ml})$ for a further $6 \mathrm{~h}$. (B) The mRNA expression of iNOS was measured by reverse transcription-quantitative polymerase chain reaction in which GAPDH was used as an internal control. (C) The production of $\mathrm{NO}$ was measured by the Griess assay. Data are presented as mean \pm standard error of the mean of six independent experiments. ${ }^{~} \mathrm{P}<0.001$ vs. control; ${ }^{* *} \mathrm{P}<0.01$ and ${ }^{* * *} \mathrm{P}<0.001$. Tanshinone IIA; VSMCs, vascular smooth muscle cells; LPS, lipopolysaccharide; NO, nitric oxide; iNOS, inducible nitric oxide synthase.

throughout the process of atherosclerosis (32). While NO is also synthesized by neuronal NOS and endothelial NOS, NO
A
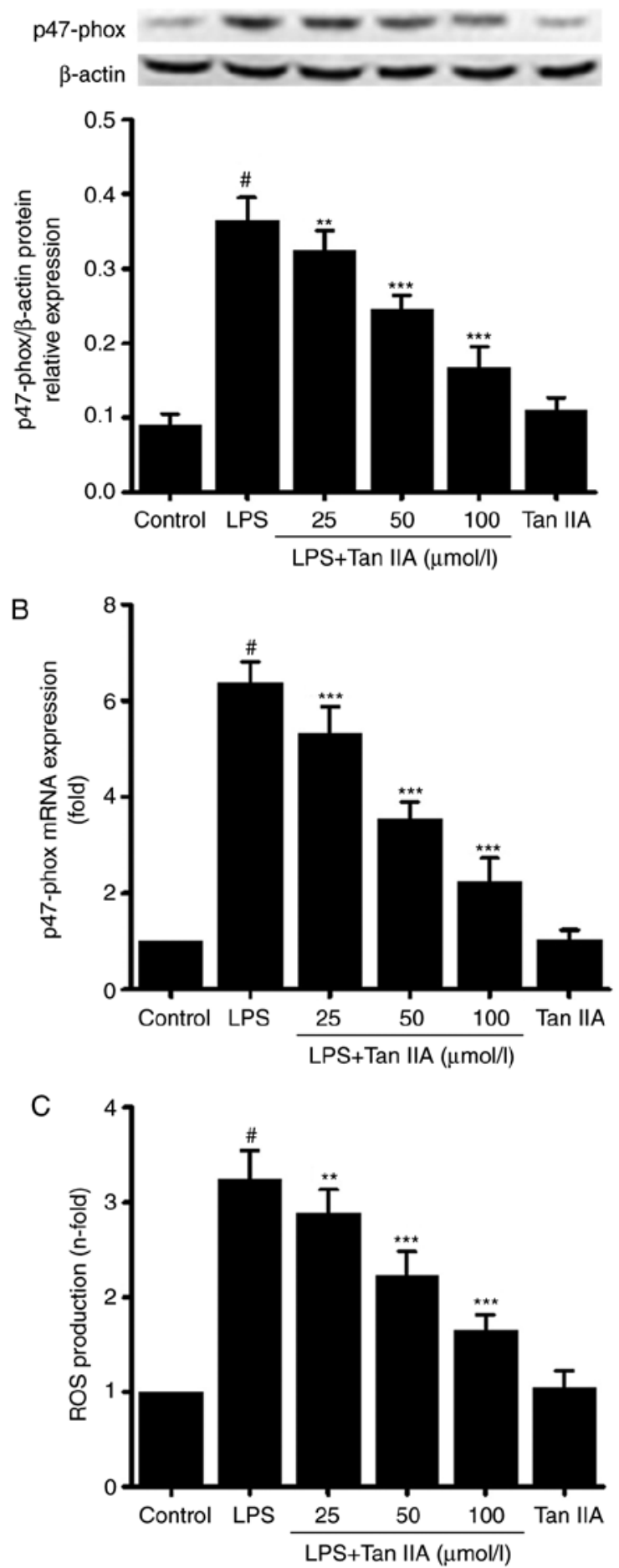

Figure 5. Tan IIA inhibits p47-phox-mediated ROS production in LPS-treated VSMCs. VSMCs were pretreated with the indicated concentrations of Tan IIA $(25,50$ and $100 \mu \mathrm{mol} / 1)$ for $1 \mathrm{~h}$ and then stimulated with LPS $(1 \mu \mathrm{g} / \mathrm{ml}$ ) for a further $24 \mathrm{~h}$ (for western blotting) or $6 \mathrm{~h}$ (for RT-qPCR). The (A) protein and (B) mRNA expression of $\mathrm{p} 47$-phox were measured by western blotting and RT-qPCR, and (C) the ROS production was detected by dichloro-dihydro-fluorescein oxidation. ${ }^{\#} \mathrm{P}<0.001$ vs. control; ${ }^{* *} \mathrm{P}<0.01$ and ${ }^{* * * *} \mathrm{P}<0.001$. Tanshinone IIA; VSMCs, vascular smooth muscle cells; LPS, lipopolysaccharide; RT-qPCR, reverse transcription-quantitative polymerase chain reaction; ROS, reactive oxygen species.

produced by iNOS is the chief contributor to the regulation of immunomodulatory activity (33). Although NO produced by the endothelium may exhibit some beneficial effects that protect endothelial function, high concentrations of NO have 
A
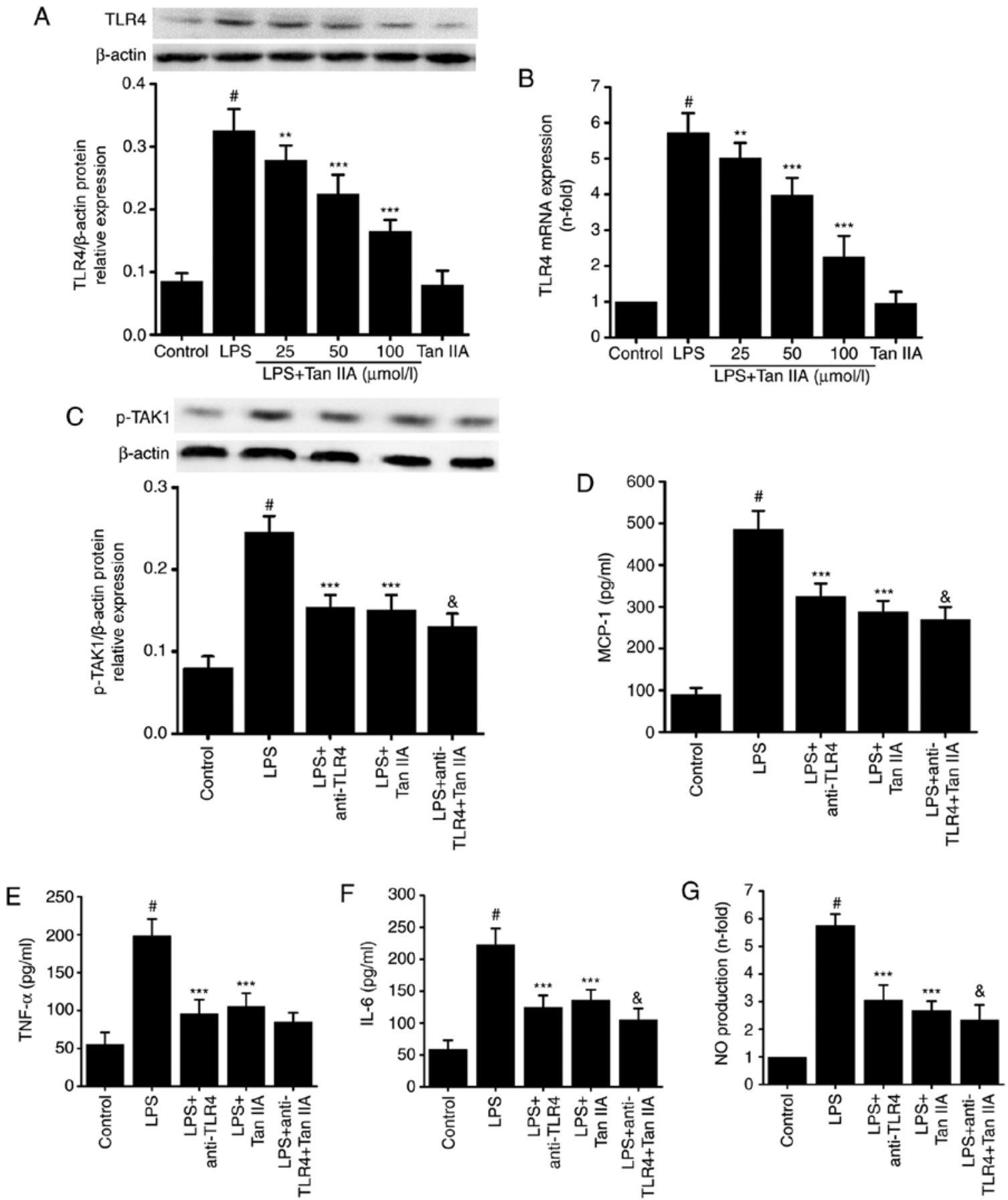

Figure 6. Association between the inhibitory effect of Tan IIA on LPS-induced inflammation and TLR4 expression in VSMCs. VSMCs were pretreated with the indicated concentrations of Tan IIA $(25,50$ and $100 \mu \mathrm{mol} / \mathrm{l})$ for $1 \mathrm{~h}$, and then stimulated with LPS $(1 \mu \mathrm{g} / \mathrm{ml})$ for a further $24 \mathrm{~h}$ (for western blotting) or $6 \mathrm{~h}$ (for RT-qPCR). The (A) protein and (B) mRNA expression of TLR4 were measured by western blotting and RT-qPCR, respectively. Cells were then pretreated with anti-TLR4 $(5 \mu \mathrm{g} / \mathrm{ml})$, Tan IIA $(100 \mu \mathrm{mol} / \mathrm{l})$, or anti-TLR4 $(5 \mu \mathrm{g} / \mathrm{ml})$ plus Tan IIA $(100 \mu \mathrm{mol} / \mathrm{l})$ for $1 \mathrm{~h}$, and then stimulated with LPS $(1 \mu \mathrm{g} / \mathrm{ml})$ for a further $24 \mathrm{~h}$. (C) The protein expression of p-TAK1 was detected by western blotting. The expression levels of (D) MCP-1, (E) TNF- $\alpha$ and (F) IL-6 were measured by an ELISA assay. (G) NO production was detected by the Griess assay. Data are presented as mean \pm standard error of the mean of six independent experiments. ${ }^{*} \mathrm{P}<0.001$ vs. control; ${ }^{* *} \mathrm{P}<0.01$ and ${ }^{* * * *} \mathrm{P}<0.001$ vs. LPS; ${ }^{\circledR} \mathrm{P}<0.05$ vs. LPS+anti-TLR4. Tanshinone IIA; VSMCs, vascular smooth muscle cells; LPS, lipopolysaccharide; RT-qPCR, reverse transcription-quantitative polymerase chain reaction; NO, nitric oxide; IL-6, interleukin-6; TNF- $\alpha$, tumor necrosis factor- $\alpha$; MCP-1, monocyte chemoattractant protein 1; TLR4, Toll-like receptor 4; p-, phosphorylated; TAK1, transforming growth factor- $\beta$-activated kinase 1.

been revealed to accelerate the progression of atherosclerosis by increasing oxidative stress (34). In addition to atherosclerosis, the overproduction of NO has also been shown to contribute to the progression of various inflammation- and immune-associated diseases, such as Alzheimer's disease (35) and Crohn's disease (36). Previous studies have demonstrated that inhibiting NO production through the use of an inhibitor of iNOS or by knockout of the iNOS gene can reduce the area of atherosclerotic plaques and attenuate plaque vulnerability in high fat diet-fed $\mathrm{ApoE}^{-/-}$mice (37). Therefore, in the present study, the effect of Tan IIA on iNOS-mediated NO production was investigated. Previous studies have demonstrated that Tan can inhibit LPS-induced and iNOS-mediated NO production in macrophages and endothelium (38). In the present study, 
A
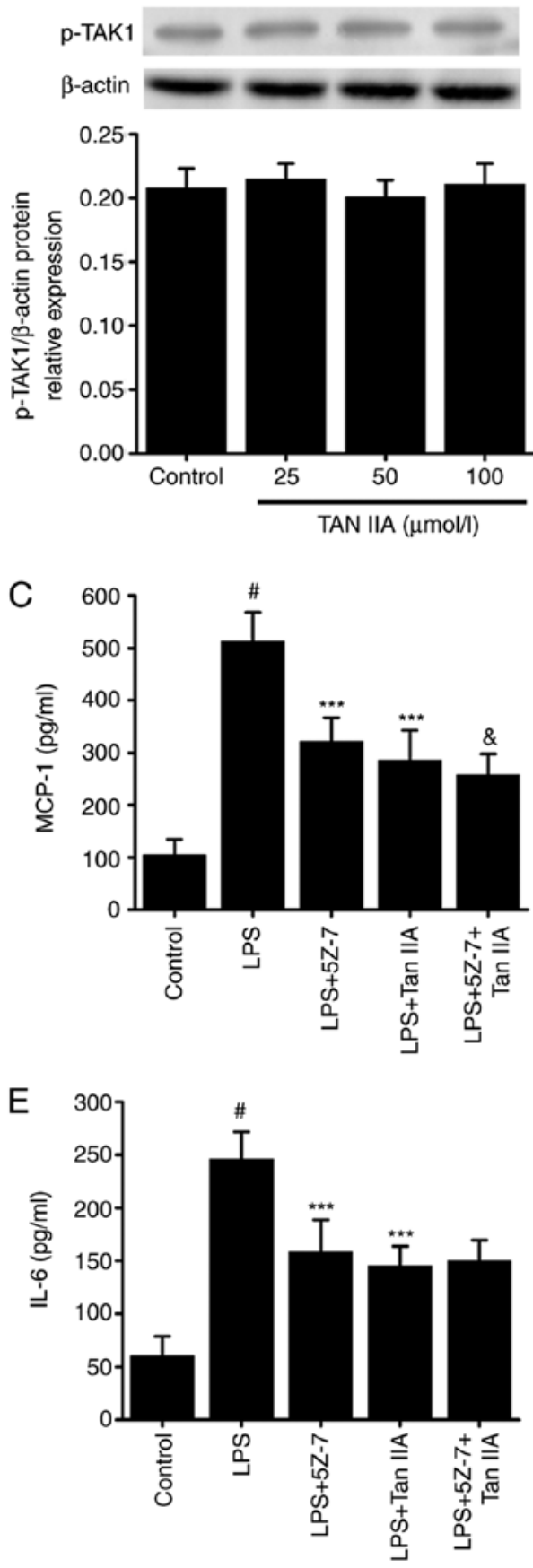

B
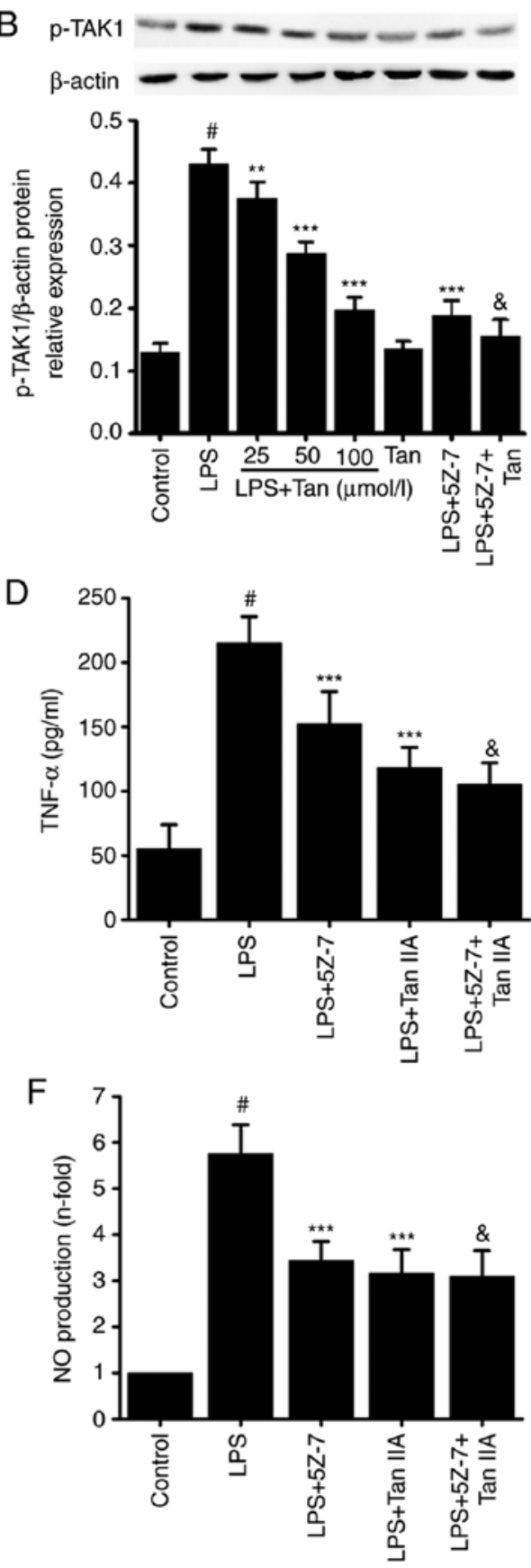

Figure 7. Associations between the inhibitory effect of Tan IIA on LPS-induced inflammation and TAK1 activation in VSMCs. (A) One group of VSMCs were only treated with Tan IIA (25, 50 and $100 \mu \mathrm{mol} / \mathrm{l})$ for $30 \mathrm{~min}$; (B) another group of cells were pretreated with the indicated concentrations of Tan IIA $(25,50$ and $100 \mu \mathrm{mol} / \mathrm{l})$ for $1 \mathrm{~h}$ and then stimulated with LPS $(1 \mu \mathrm{g} / \mathrm{ml})$ for a further $30 \mathrm{~min}$. The levels of p-TAK1 was measured by western blotting. Cells were pretreated with 5Z-7-oxozeaenol $(0.5 \mu \mathrm{mol} / \mathrm{l})$, Tan IIA $(100 \mu \mathrm{mol} / 1)$, or $5 \mathrm{Z}-7$-oxozeaenol $(0.5 \mu \mathrm{mol} / \mathrm{l})$ plus Tan IIA $(100 \mu \mathrm{mol} / 1)$ for $1 \mathrm{~h}$ and then stimulated with LPS $(1 \mu \mathrm{g} / \mathrm{ml})$ for a further $24 \mathrm{~h}$. The protein expression of (C) MCP-1, (D) TNF- $\alpha$ and (E) IL-6 was measured by an ELISA assay. (F) NO production was detected by the Griess assay. Data are presented as mean \pm standard error of the mean from six independent experiments. ${ }^{*} \mathrm{P}<0.001$ vs. control; ${ }^{* *} \mathrm{P}<0.01$ and ${ }^{* * *} \mathrm{P}<0.001$ vs. LPS; ${ }^{\text {\& }} \mathrm{P}<0.05$ vs. LPS+5Z-7-oxozeaenol. Tanshinone IIA; VSMCs, vascular smooth muscle cells; LPS, lipopolysaccharide; NO, nitric oxide; IL-6, interleukin-6; TNF- $\alpha$, tumor necrosis factor- $\alpha$; MCP-1, monocyte chemoattractant protein 1; p-, phosphorylated; TAK1, transforming growth factor- $\beta$-activated kinase $1 ; 5 Z-7,5 Z-7$-oxozeaenol.

Tan IIA significantly inhibited LPS-induced NO production, which was accompanied by a reduction in iNOS expression. These results suggest that Tan IIA suppresses iNOS-mediated NO production in LPS-stimulated VSMCs, which may provide a novel molecular mechanism for the cardiovascular protective effect of Tan IIA.

Previous evidence has demonstrated that the activation of TLR4 serves an important role in the acceleration of atherosclerosis by inducing an excessive inflammatory response (9). In human and animal models, an increase in TLR4 expression has been observed in atherosclerotic plaques, which was accompanied by an overexpression of various inflammation-associated factors (39). Our previous study also demonstrated that LPS increases the expression of TLR4 in VSMCs (4). However, when given the same high-cholesterol diet, TLR4-knockout mice exhibited a reduction in 

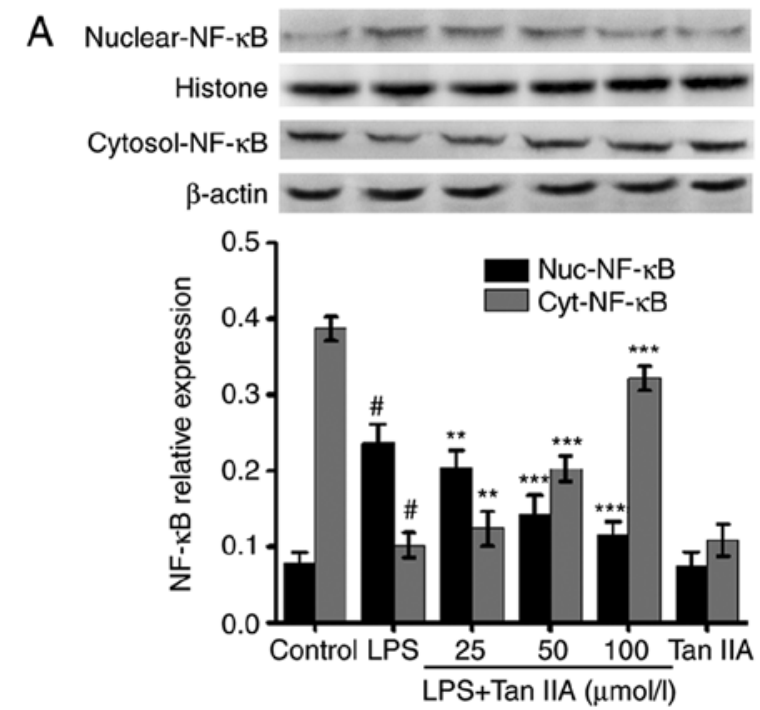

B
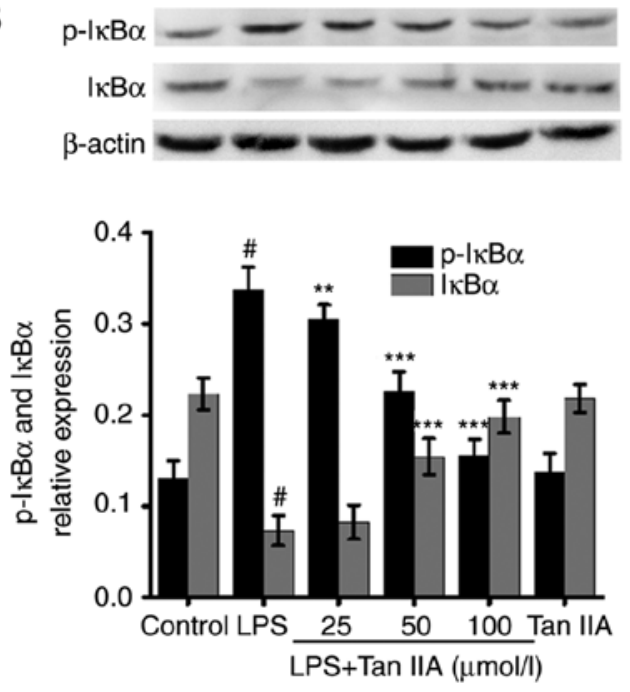

Figure 8. Tan IIA inhibits LPS-induced NF- $\mathrm{B}$ activation in VSMCs. VSMCs were pretreated with the indicated concentrations of Tan IIA $(25,50$ and $100 \mu$ mol/1) for $1 \mathrm{~h}$ and then stimulated with LPS $(1 \mu \mathrm{g} / \mathrm{ml}$ ) for a further 24 (for NF- $\kappa \mathrm{B}$ ) or $6 \mathrm{~h}$ (for $\mathrm{p}-\mathrm{I} \kappa \mathrm{B} \alpha$ ). The protein expression of (A) NF- $\kappa \mathrm{B}$ (p65) in nuclei and (B) $\mathrm{p}-\mathrm{I} \kappa \mathrm{B} \alpha$ were measured by western blotting, in which histone and $\beta$-actin were used as internal controls, respectively. Data are presented as the mean \pm standard error of the mean of six independent experiments. ${ }^{\#} \mathrm{P}<0.001$ vs. control; ${ }^{* *} \mathrm{P}<0.01$ and ${ }^{* * *} \mathrm{P}<0.001$ vs. LPS. Tanshinone IIA; VSMCs, vascular smooth muscle cells; LPS,

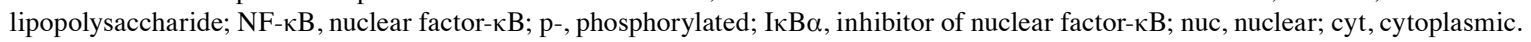

atherosclerotic plaque area and had more stable plaques when compared with normal ApoE ${ }^{-/}$mice (39). In addition, the activation of the TLR4 signaling pathway serves an important role in NO production in LPS-stimulated VSMCs (40). Therefore, it is valid to consider that inhibiting TLR4 activation may be an effective strategy to impede the progress of atherosclerosis. A previous study demonstrated that Tans can reduce the LPS-induced expression of TLR4 in macrophages (19). In the present study, Tan IIA inhibited the LPS-induced expression of TLR4 at the mRNA and protein levels in a concentration-dependent manner. This was accompanied by a reduction in the production of pro-inflammatory cytokines. Furthermore, the monoclonal antibody of TLR4 exhibited the same anti-inflammatory effects as Tan IIA, and treatment with a combination of Tan IIA and the TLR4 monoclonal antibody resulted in a more powerful inhibitory effect on LPS-induced inflammation. These results indicate that the inhibition of TLR4 activation may be involved in the anti-inflammatory effect of Tan IIA in LPS-stimulated VSMCs.

As an important downstream molecule, TAK1 serves a critical role in the TLR-mediated inflammatory signaling pathway. Once LPS binds to the CD14/TLR4 complex, TLR4 is activated. Then, Myd88 induces the phosphorylation of IL-1 receptor-associated kinase 4 (IRAK4) and IRAK1, which results in the phosphorylation of TAK1 (41). Activated TAK1 induces the phosphorylation of MAPKs and IKKs, which are the main factors that regulate $N F-\kappa B$ activation (42). Tans have been shown to inhibit the LPS-induced activation of $\mathrm{NF}-\kappa \mathrm{B}$ by reducing TAK1 expression in macrophages (19). In addition, a previous study evaluated the effects of Tan IIA on atherosclerotic vulnerable plaque stability (43). Tans were reported to also decrease $\mathrm{NF}-\kappa \mathrm{B}$ activation in VSMCs, which in turn inhibited VSMC proliferation and migration (43). As a conventional regulator of $\mathrm{NF}-\kappa \mathrm{B}$, these results indicated that TAK1 may also be involved in the mechanisms underlying $\mathrm{NF}-\kappa \mathrm{B}$ inactivation by Tan IIA in VSMCs. In the present study, Tan IIA induced effects similar to those of the TAK1 inhibitor. Tan IIA attenuated the LPS-induced expression of p-TAK1 in a concentration-dependent manner and inhibited the LPS-induced expression of MCP-1, IL-6, TNF- $\alpha$, and NO in VSMCs. These results suggest that the inhibition of TAK1 activation may be involved in the anti-inflammatory effect of Tan IIA in LPS-stimulated VSMCs.

$\mathrm{NF}-\kappa \mathrm{B}$ is a ubiquitously expressed nuclear transcription factor that is considered to be associated with inflammation, especially in the expression of cytokines. Activation of $\mathrm{NF}-\kappa \mathrm{B}$ occurs when it is isolated from I $\mathrm{B} \mathrm{B} \alpha$. Once I $\mathrm{I} \mathrm{B} \alpha$ is phosphorylated, it degrades and allows NF- $\mathrm{B}$ to become activated, and then $N F-\kappa B$ is translocated from the cytosol into the nucleus where it can control DNA transcription. Following cell stimulation with LPS, the level of $\mathrm{p}-\mathrm{I} \kappa \mathrm{B} \alpha$ was increased while the level of total $\mathrm{I} \kappa \mathrm{B} \alpha$ was decreased, which was consistent with the results of some previous studies $(44,45)$. Many signaling pathways result in $\mathrm{NF}-\kappa \mathrm{B}$ phosphorylation, which causes $\mathrm{NF}-\kappa \mathrm{B}$ to hydrolyze into several subunits (46). One of the subunits is P65, which translocates to the nucleus to bind to DNA. It then upregulates the expression of cytokines, including MCP-1, IL-6, TNF- $\alpha$, and NO (47). Several studies have indicated that $\mathrm{NF}-\kappa \mathrm{B}$ may serve an important role in LPS-induced inflammation in macrophages and VSMCs $(48,49)$. As a downstream molecule of TAK1, a reduction in NF- $\kappa \mathrm{B}$ may contribute to the anti-inflammatory mechanism of Tan IIA. In the present study, it was observed that pretreatment with Tan IIA attenuated the LPS-induced nuclear translocation of NF- $\kappa$ B (p65) in VSMCs in a dose-dependent manner, which suggests that Tan IIA may inhibit LPS-induced NF- $\kappa \mathrm{B}$ activation in VSMCs.

In conclusion, the present study demonstrated the anti-inflammatory properties of Tan IIA in VSMCs by inhibiting MCP-1, IL-6, TNF- $\alpha$, and NO. These effects may be mediated by downregulating TLR4 and inhibiting TAK1, which consequently leads to the inhibition of $N F-\kappa B$ activation and eventually the suppression of its target genes. The present 
study provided a novel experimental basis for using Tan IIA as a therapeutic agent to treat chronic inflammation-mediated diseases, especially atherosclerosis.

\section{Acknowledgements}

The authors would like to thank Professor Li Ling (Department of Cardiology, The First Affiliated Hospital of Zhengzhou University, Zhengzhou, Henan, China) for assisting with the experimental lab work.

\section{Funding}

The present study was supported by the Youth Foundation of The First Affiliated Hospital of Zhengzhou University (grant no. YFFAHZZ 2015020105).

\section{Availability of data and materials}

All data generated or analyzed during this study are included in this published article.

\section{Authors' contributions}

HYL conceived and designed the study. ZM conducted the majority of the experiments and wrote the paper. CYS, ST and XHY performed the experiments. All authors read and approved the final manuscript.

\section{Ethics approval and consent to participate}

The present study was carried out in strict accordance with the Guide for the Care and Use of Laboratory Animals published by the US National Institutes of Health (NIH Publication no. 85-23, revised 1996) and was approved by the Ethics and Animal Welfare Committee of Zhengzhou University (Henan, China).

\section{Patient consent for publication}

Not applicable.

\section{Competing interests}

The authors declare that they have no competing interests.

\section{References}

1. Hansson GK, Libby $P$ and Tabas I: Inflammation and plaque vulnerability. J Intern Med 278: 483-493, 2015.

2. de Vries MR and Quax PH: Plaque angiogenesis and its relation to inflammation and atherosclerotic plaque destabilization. Curr Opin Lipidol 27: 499-506, 2016.

3. Chistiakov DA, Orekhov AN and Bobryshev Y V: Vascular smooth muscle cell in atherosclerosis. Acta Physiol (Oxf) 214: 33-50, 2015.

4. Meng Z, Yan C, Deng Q, Gao DF and Niu XL: Curcumin inhibits LPS-induced inflammation in rat vascular smooth muscle cells in vitro via ROS-relative TLR4-MAPK/NF- $\kappa$ B pathways. Acta Pharmacol Sin 34: 901-911, 2013.

5. Son YH, Jeong YT, Lee KA, Choi KH, Kim SM, Rhim BY and Kim K: Roles of MAPK and NF-kappaB in interleukin-6 induction by lipopolysaccharide in vascular smooth muscle cells. J Cardiovasc Pharmacol 51: 71-77, 2008.
6. Dickson BC and Gotlieb AI: Towards understanding acute destabilization of vulnerable atherosclerotic plaques. Cardiovasc Pathol 12: 237-248, 2003.

7. Minguet S, Dopfer EP, Pollmer C, Freudenberg MA, Galanos C, Reth M, Huber M and Schamel WW: Enhanced B-cell activation mediated by TLR4 and BCR crosstalk. Eur J Immunol 38: 2475-2487, 2008.

8. Roshan MH, Tambo A and Pace NP: The Role of TLR2 TLR4, and TLR9 in the Pathogenesis of Atherosclerosis. Int J Inflam 2016: 1532832, 2016.

9. Lu Z,Zhang X, Li Y, Jin J and Huang Y: TLR4 antagonist reduces early-stage atherosclerosis in diabetic apolipoprotein E-deficient mice. J Endocrinol 216: 61-71, 2013.

10. Edfeldt K, Swedenborg J, Hansson GK and Yan ZQ: Expression of toll-like receptors in human atherosclerotic lesions: A possible pathway for plaque activation. Circulation 105: 1158-1161, 2002.

11. Michelsen KS, Wong MH, Shah PK, Zhang W, Yano J, Doherty TM, Akira S, Rajavashisth TB and Arditi M: Lack of Toll-like receptor 4 or myeloid differentiation factor 88 reduces atherosclerosis and alters plaque phenotype in mice deficient in apolipoprotein E. Proc Natl Acad Sci USA 101: 10679-10684, 2004.

12. Ajibade AA, Wang HY and Wang RF: Cell type-specific function of TAK1 in innate immune signaling. Trends Immunol 34: 307-316, 2013.

13. Yao X,Li G, Bai Q, Xu H and Lü C: Taraxerol inhibits LPS-induced inflammatory responses through suppression of TAK1 and Akt activation. Int Immunopharmacol 15: 316-324, 2013.

14. Fang J, Little PJ and Xu S: Atheroprotective effects and molecular targets of tanshinones derived from herbal medicine danshen. Med Res Rev 38: 201-228, 2018.

15. Fan K, Li S, Liu G, Yuan H, Ma L and Lu P: Tanshinone IIA inhibits high glucose-induced proliferation, migration and vascularization of human retinal endothelial cells. Mol Med Rep 16 9023-9028, 2017.

16. Li S, Jiao Y, Wang H, Shang Q, Lu F, Huang L, Liu J, Xu H and Chen K: Sodium tanshinone IIA sulfate adjunct therapy reduces high-sensitivity C-reactive protein level in coronary artery disease patients: A randomized controlled trial. Sci Rep 7: 17451, 2017.

17. Hu H, Zhai C, Qian G, Gu A, Liu J, Ying F, Xu W, Jin D, Wang H $\mathrm{Hu} \mathrm{H}$, et al: Protective effects of tanshinone IIA on myocardial ischemia reperfusion injury by reducing oxidative stress, HMGB1 expression, and inflammatory reaction. Pharm Biol 53: $1752-1758,2015$

18. Sui H, Zhao J, Zhou L, Wen H, Deng W, Li C, Ji Q, Liu X, Feng Y, Chai N, et al: Tanshinone IIA inhibits $\beta$-catenin/VEGF-mediated angiogenesis by targeting TGF- $\beta 1$ in normoxic and HIF-1 $\alpha$ in hypoxic microenvironments in human colorectal cancer. Cancer Lett 403: 86-97, 2017.

19. Fan G, Jiang X, Wu X, Fordjour PA, Miao L, Zhang H, Zhu Y and Gao X: Anti-Inflammatory activity of tanshinone IIA in LPS-stimulated RAW264.7 macrophages via miRNAs and TLR4-NF-кB PATHWAY. Inflammation 39: 375-384, 2016.

20. National Research Council: Guide for the Care and Use of Laboratory Animals. National Academy Press, Washington, DC, 1996.

21. Griendling KK, Taubman MB, Akers M, Mendlowitz M and Alexander RW: Characterization of phosphatidylinositol-specific phospholipase $\mathrm{C}$ from cultured vascular smooth muscle cells. J Biol Chem 266: 15498-15504, 1991.

22. Cho JY, Baik KU, Jung JH and Park MH: In vitro anti-inflammatory effects of cynaropicrin, a sesquiterpene lactone, from Saussurea lappa. Eur J Pharmacol 398: 399-407, 2000.

23. Zhou W, Wang G, Zhao X, Xiong F, Zhou S, Peng J, Cheng Y, $\mathrm{Xu} \mathrm{S}$ and $\mathrm{Xu} \mathrm{X}$ : A multiplex qPCR gene dosage assay for rapid genotyping and large-scale population screening for deletional $\alpha$-thalassemia. J Mol Diagn 15: 642-651, 2013.

24. Cao L, Pan D, Li D, Zhang Y, Chen Q, Xu T, Li W and Wu W: Relation between anti-atherosclerotic effects of IRAK4 and modulation of vascular smooth muscle cell phenotype in diabetic rats. Am J Transl Res 8: 899-910, 2016.

25. Meng Z, Gao P, Chen L, Peng J, Huang J, Wu M, Chen K and Zhou Z: Artificial zinc-finger transcription factor of A20 suppresses restenosis in sprague dawley rats after carotid injury via the PPAR $\alpha$ pathway. Mol Ther Nucleic Acids 15: 123-131, 2017.

26. Chen FL, Yang ZH, Wang XC, Liu Y, Yang YH, Li LX, Liang WC, Zhou WB and Hu RM: Adipophilin affects the expression of TNF-alpha, MCP-1, and IL-6 in THP-1 macrophages. Mol Cell Biochem 337: 193-199, 2010. 
27. Konev IuV and Lazebnik LB: Endotoxin (LPS) in the pathogenesis of atherosclerosis. Eksp Klin Gastroenterol: 15-26, 2011 (In Russian).

28. Li Y, Guo Y, Chen Y, Wang Y, You Y, Yang Q, Weng X, Li Q, Zhu X, Zhou B, et al: Establishment of an interleukin-1 $\beta$-induced inflammation-activated endothelial cell-smooth muscle cell-mononuclear cell co-culture model and evaluation of the anti-inflammatory effects of tanshinone IIA on atherosclerosis. Mol Med Rep 12: 1665-1676, 2015.

29. Li J, Zheng Y, Li MX, Yang CW and Liu YF: Tanshinone IIA alleviates lipopolysaccharide-induced acute lung injury by downregulating TRPM7 and pro-inflammatory factors. J Cell Mol Med 22: 646-654, 2018.

30. Cheng J, Chen T, Li P, Wen J, Pang N, Zhang L and Wang L: Sodium tanshinone IIA sulfonate prevents lipopolysaccharide-induced inflammation via suppressing nuclear factor- $\kappa \mathrm{B}$ signaling pathway in human umbilical vein endothelial cells. Can J Physiol Pharmacol 96: 26-31, 2018.

31. Wang B, Ge Z, Cheng Z and Zhao Z: Tanshinone IIA suppresses the progression of atherosclerosis by inhibiting the apoptosis of vascular smooth muscle cells and the proliferation and migration of macrophages induced by ox-LDL. Biol Open 6: 489-495, 2017.

32. Shaw CA, Taylor EL, Megson IL and Rossi AG: Nitric oxide and the resolution of inflammation: Implications for atherosclerosis. Mem Inst Oswaldo Cruz 100 (Suppl 1): S67-S71, 2005.

33. Caillaud D, Galinier M, Elbaz M, Carrié D, Puel J, Fauvel JM and Arnal JF: Atherosclerosis-the role of nitric oxide. Presse Med 30: 41-44, 2001 (In French).

34. Förstermann U, Xia N and Li H: Roles of vascular oxidative stress and nitric oxide in the pathogenesis of atherosclerosis. Circ Res 120: 713-735, 2017.

35. Asiimwe N, Yeo SG, Kim MS, Jung J and Jeong NY: Nitric oxide: Exploring the contextual link with Alzheimer's disease. Oxid Med Cell Longev 2016: 7205747, 2016.

36. Heydarpour P, Rahimian R, Fakhfouri G, Khoshkish S, Fakhraei N, Salehi-Sadaghiani M, Wang H, Abbasi A, Dehpour AR and Ghia JE: Behavioral despair associated with a mouse model of Crohn's disease: Role of nitric oxide pathway. Prog Neuropsychopharmacol Biol Psychiatry 64: 131-141, 2016.

37. Detmers PA, Hernandez M, Mudgett J, Hassing H, Burton C, Mundt S, Chun S, Fletcher D, Card DJ, Lisnock J, et al: Deficiency in inducible nitric oxide synthase results in reduced atherosclerosis in apolipoprotein E-deficient mice. J Immunol 165 : 3430-3435, 2000.

38. Liu XH, Wang XL, Xin H, Wu D, Xin XM, Miao L, Zhang QY, Zhou Y, Liu Q, Zhang Q and Zhu YZ: Induction of heme oxygenase-1 by sodium 9-hydroxyltanshinone IIA sulfonate derivative contributes to inhibit LPS-mediated inflammatory response in macrophages. Cell Physiol Biochem 36: 1316-1330, 2015.
39. Gargiulo S, Gamba P, Testa G, Rossin D, Biasi F, Poli G and Leonarduzzi G: Relation between TLR4/NF- $\mathrm{B}$ signaling pathway activation by 27-hydroxycholesterol and 4-hydroxynonenal, and atherosclerotic plaque instability. Aging Cell 14: 569-581, 2015.

40. Nunes KP, Bomfim GF, Toque HA, Szasz T and Clinton Webb R: Toll-like receptor 4 (TLR4) impairs nitric oxide contributing to Angiotensin II-induced cavernosal dysfunction. Life Sci 191: 219-226, 2017.

41. He A, Ji R, Shao J, He C, Jin M and Xu Y: TLR4-MyD88TRAF6-TAK1 complex-mediated NF- $\kappa \mathrm{B}$ activation contribute to the anti-inflammatory effect of V8 in LPS-induced human cervical cancer SiHa cells. Inflammation 39: 172-181, 2016.

42. Shim JH, Xiao C, Paschal AE, Bailey ST, Rao P, Hayden MS, Lee KY, Bussey C, Steckel M, Tanaka N, et al: TAK1, but not TAB1 or TAB2, plays an essential role in multiple signaling pathways in vivo. Genes Dev 19: 2668-2681, 2005.

43. Wu WY, Yan H, Wang XB, Gui YZ, Gao F, Tang XL, Qin YL, Su M, Chen T and Wang YP: Sodium tanshinone IIA silate inhibits high glucose-induced vascular smooth muscle cell proliferation and migration through activation of AMP-activated protein kinase. PLoS One 9: e94957, 2014.

44. Chen CL, Chen JT, Liang CM, Tai MC, Lu DW and Chen YH: Silibinin treatment prevents endotoxin-induced uveitis in rats in vivo and in vitro. PLoS One 12: e0174971, 2017.

45. Bhatia HS, Baron J, Hagl S, Eckert GP and Fiebich BL: Rice bran derivatives alleviate microglia activation: Possible involvement of MAPK pathway. J Neuroinflammation 13: 148-155, 2016.

46. Ghosh S and Dass JF: Study of pathway cross-talk interactions with NF- $\kappa B$ leading to its activation via ubiquitination or phosphorylation: A brief review. Gene 584: 97-109, 2016.

47. Chen XW and Zhou SF: Inflammation, cytokines, the IL-17/IL-6/STAT3/NF- $\kappa$ B axis, and tumorigenesis. Drug Des Devel Ther 9: 2941-2946, 2015

48. Kim KJ, Yoon KY, Yoon HS, Oh SR and Lee BY: Brazilein suppresses inflammation through inactivation of IRAK4-NF- $\kappa B$ pathway in LPS-induced Raw264.7 macrophage cells. Int J Mol Sci 16: 27589-27598, 2015.

49. Yang HL, Huang PJ, Liu YR, Kumar KJ, Hsu LS, Lu TL, Chia YC, Takajo T, Kazunori A and Hseu YC: Toona sinensis inhibits LPS-induced inflammation and migration in vascular smooth muscle cells via suppression of reactive oxygen species and NF- $\mathrm{KB}$ signaling pathway. Oxid Med Cell Longev 2014: 901315,2014 